\title{
Rethinking Digital Games in a Critical and Participatory Perspectives. A Brief Reflection
}

\author{
Patrícia da Silva Leite \\ (Federal University of Technology, Paraná; patriciasleite@gmail.com) \\ ORCID: 0000-0003-4934-3584 \\ Deborah Andrade Torquato Schimidt \\ (University of Montreal; deborahtorquato@gmail.com) \\ ORCID: 0000-0003-3822-9831
}

Digital games are increasingly present in our society which bring positive contributions and also new issues linked to their technological, social and cultural spheres. They are a human construction historically situated which reproduce, incorporate and shape discourses and worldviews. Regarding its technological facet, Feenberg (2010) argues that our society is organized around technology and confronts the neutral view of technology, which is strongly rooted in the concept of efficiency from instrumental rationality. This notion considers technology as a tool for human being service disconnected from ethical, social and political implications. However, as a human construction, technology carries a non-neutral character and is often used as a source of power and social battlefield (Feenberg 2002; 2010). Thus, technology cannot be understood as a collection of devices displaced from their context. Instead, technology must be recognized as a social object structured in cultural, ethical, and political ambits. Based on this understanding, we conceive digital games as socially constructed technologies that also embrace fun and social aspects. In this work, we seek to discuss its particular characteristics from a critical theory perspective.

Huizinga (2014) was a pioneer to discuss games features and unfoldings for society from an understanding that playing games in general is one of the human activities that enable people to express their experiences of life and world interpretations. Along these lines, games can be used as a way to perform actions such as excessive energy discharge, preparation for life demands, and other activities. And more than physical, biological, or psychological activity, games can be considered as a cultural and social function (Huizinga 2014). Therefore, playing is a way that player can be in the world and understand what surrounds them acknowledging who they are, what they can mean to the world and how they can get involved with other people (Sicart 2014; Leite 2018). 
Playing and games are human manifestations, to express and situate themselves in the world, as well as in art, literature, music, dance and politics (Sicart 2014). Through playing people can have the opportunity to distance themselves in a critical perspective and experience problem-solving and decision-making processes (Schimidt 2017; Sicart 2014). Hence, people can reflect and decide in a critical way what values could be part of their lives. In this way, we can assume an intrinsic correlation between games and society, especially with the use of technology as an element to shape and represent human and social life (Egenfeldt-Nielsen, Smith, \& Tosca 2008; Leite, Retore \& Almeida 2019).

In this work, we understand digital games as a space that allows the development of social interactions for social integration (Grimes \& Feenberg 2009; Schimidt 2017). Based on the critical theory of technology (Feenberg 2001; 2002; 2010), we conceive digital games beyond an instrumental view seeking to reflect on its emancipatory and participatory perspectives (Freire 2014; 2015). In order to discuss these aspects, we present brief reflections from two researches developed by the authors involving social interactions on digital games.

Our first discussion involves digital games and accessibility regarding people with disabilities. Considering games as a medium used to express and experience social and cultural values. Like other entertainment media, digital games need to be accessible to all people, including people with disabilities (Leite et al. 2019). In Leite, Retore, and Almeida (2019) research is articulated digital game elements with the social inclusion general principles of the Convention on the Rights of Persons with Disabilities (CRPD) (United Nations, 2019). The authors present reflections on how digital games can be understood with CRPD principles, examples of how these principles can be identified in games, and connections between accessibility guidelines to CRPD principles.

An example presented in Leite et al. (2019) is the accessibility feature implemented in PlayStation 4, which considers people with low vision who can increase the size of screen's parts. This feature can be related to CRPD principles such as respect, autonomy, and freedom; respect for differences; and equality of opportunity. Another example is the game Frequency Missing that presents an inclusive narrative to provide similar experiences to people with and without visual disabilities and can be related to CRPD principles non-discrimination, equality of opportunity, and accessibility. Games such as Dishonored 2 and Horizon Zero Dawn can be related to principles of respect for differences and equality of opportunities, because of these games provide several ways to meet the different game goals (Leite et al. 2019).

This discussion highlights other perspectives on the relationship between CRPD principles and digital games resulting in a set of reflections for an inclusive design on digital games regarding people with disabilities. With such study game developers can find other means to ensure that the digital game elements are properly implemented, enabling an entertaining and engaging experience that reaches as many people as possible. Besides that, the development of inclusive digital games highlights the possibility to expand 
discussions about technology development into a more democratic and comprehensive scale (Leite et al. 2019).

Our second discussion concerns the insertion of digital games in educational context. According to the research conducted by Schimidt (2017), digital games can provide the development of formative actions within the school's environment. The author highlights the importance of a critical grounding that redefines education and technology visions in order to reframe both learning process and technology meaning. Based on Theory of Dialogical Action (Freire 2014; 2015) and Theory of Communicative Action (Habermas 1984; 1987), Schimidt (2017) developed the concept of communicative environment as a formative proposal. This theoretical construct is comprehended by a non-coercive communication environment seeking to establish a consensus through argument-based discussion. In this way, people could develop an action-reflection process seeking a reflexive praxis based on communication and critical thinking.

In Schimidt (2017), the concept of communicative environment was applied on pedagogical actions developed inside the virtual world of the digital game Minecraft. The research was accomplished in a public school in Curitiba (Brazil) with secondary students. Differently from other research involving Minecraft and education, the educational actions were structured in a collective and participatory way requiring students to work collaboratively, even inside the game. According to the results presented, Schimidt (2017) emphasizes that the game was a fundamental part for the development of discussions, collaborative actions, and collective constructions (Schimidt \& Sutil 2019). Through Minecraft's virtual world, students have discussed and developed proposals and actions relating scientific knowledge with the real and virtual worlds. Based on this research, we understand that a critical view of digital games can contribute to critical learning process as it can provide a praxis-based in learning and participatory environment.

These two researches exemplify critical perspectives of digital games and highlight their potential for social integration and human formation. From a critical perspective, digital games can provide a space for people's participation and social transformation. This understanding of digital games offer means to redefine technology itself going beyond its technical uses and specifications. Be from the empowerment of non-dominant groups in society or even from the collaborative action of people in the virtual space, the critical view of digital games seeks to explore new ways to develop, discuss, and understand these technological, social, and cultural artifacts.

This article aims to bring to the discussion the issue of digital games in society highlighting their contributions and potentialities within a critical thinking. We consider that it is crucial to address these issues due to the current context in which digital games end up being restricted to instrumental, commercial, and pure entertainment views. These perceptions may mask the real effects of digital games on society reducing to the market logic. In this way, we look for unveil its complex context taking into account its range of facets in our society (cultural, political, historical, among others). Through this 
position, we hope that games be recognized, created, developed and played as the social objects they are. And finally, that our society starts to create games that are more inclusive and critical, pursuing to explore their benefits, and also understanding their limitations and implications.

\section{References}

Egenfeldt-Nielsen S., Smith J. H., \& Tosca S. P. 2008. Understanding Video Games: The Essential Introduction. New York: Routledge.

Feenberg A. 2001. "Democratizing Technology: Interests, Codes, Rights." The Journal of Ethics (5):177-195. Netherlands: Kluwer Academic Publishers.

Feenberg A. 2002. Transforming Technology: A Critical Theory Revisited. New York: Oxford University Press.

Feenberg A. 2010. Between Reason and Experience: Essays in Technology and Modernity. Cambridge: MIT Press.

Freire P. 2014. Educação e mudança [Education and change]. São Paulo: Paz e Terra.

Freire P. 2015. Pedagogy of the Oppressed. New York: Bloomsburry Academic.

Grimes S. M. \& Feenberg A. 2009. "Rationalizing Play: A Critical Theory of Digital Gaming." The Information Society 25(2):105-18.

Habermas J. 1984. The Theory of Communicative Action (Vol. 1). Boston: Beacon Press.

Habermas J. 1987. The Theory of Communicative Action (Vol. 2). Boston: Beacon Press.

Huizinga J. 2014. Homo ludens: o jogo como elemento da cultura [Homo ludens: Game as a cultural element]. São Paulo: Perspectiva.

Leite P. S. 2018. Elementos de jogos digitais inclusivos para gameplay no contexto das pessoas com deficiência sob a perspectiva da interação corporificada [Inclusive digital game elements for gameplay in the context of people with disabilities through embodied interaction perspective] (Master's thesis). Postgraduate Program of Technology and Society, Federal University of Paraná, Brazil.

Leite P. S., Retore A. P., \& Almeida L. D. A. 2019. "Reflections on Elements of a Game Design Model Applied to Inclusive Digital Games." in: Universal Access in HumanComputer Interaction. Theory, Methods and Tools. HCII 2019 (pp. 284-300).

Schimidt D. A. T. 2017. Espaços comunicativos e jogos digitais: processos formativos com a inserção do jogo digital Minecraft no contexto do ensino superior e da educação básica [Communicative environment and video games: formative processes with Minecraft video game insertion on Higher Education and Secondary Education] (Master's thesis). Postgraduate program of Science and Mathematics Education, Federal University of Technology, Paraná, Brazil. 
Schimidt D. T. \& Sutil N. 2019. "The Development of Communicative Environment in the Minecraft Virtual World: Experiences with Secondary School Students." Papers of Canadian International Conference on Advances in Education, Teaching \& Technology 2018 (p. 111-8).

Sicart M. 2014. Play Matters. Cambridge, Massachusetts: MIT Press.

United Nations. 2019. Convention on the rights of persons with disabilities (CRPD). https://www.un.org/development/desa/disabilities/conventionon-the-rights-ofpersons-with-disabilities.html 


\title{
Patrícia da Silva Leite (Paraná) \\ Deborah Andrade Torquato Schimidt (Montreal)
}

\section{Rethinking Digital Games in a Critical and Participatory Perspectives. A Brief Reflection}

\begin{abstract}
Digital games are social objects created based on our culture and society and at the same time they contribute to shaping our world. Through a critical perspective of digital games and technology, it is possible to discuss the unfolding of these artefacts in our society and also understand their relevance beyond an instrumental view. In this paper, we present a brief reflection based on two researches developed by the authors: the first, regarding the link between digital games and people with disabilities; and the second, about contributions of digital games to a critical education. Our goal with this work is to highlight the emancipatory and participatory potential present in the critical vision of digital games.
\end{abstract}

Keywords: digital games; Critical Theory; disability; people with disabilities; education; Freire; Habermas.

Ethics in Progress (ISSN 2084-9257). Vol. 10 (2019). No. 2, Art. \#10, pp. 112-117.

Creative Commons BY-SA 4.0

DOI:10.14746/eip.2019.2.10 